\title{
DESIGN OPTIMISATION OF EMBRAER FUSELAGE WITH EXPLICIT DYNAMIC ANALYSIS
}

\author{
S. K. VEEKSHITH \\ P. G. Student \\ Industrial Automation and Robotics, \\ Department of Mechanical Engineering, \\ Malnad College of Engineering, Hassan, Karnataka, \\ India
}

\begin{abstract}
The motive of this work is to compare the effectiveness of CFRP material with Aluminum alloy on the Aircraft fuselage of Embraer E-190 and how well can CFRP material act while the emergency situations when the landing gears are non-functional and the aircraft needs to be landed without the aid of the landing gears. This leads to the condition that the aircraft needs a landing only on the fuselage part also referred as belly landing situation. So the material of the fuselage needs to be analyzed for a drop test.
\end{abstract}

This work is aimed to analyze the aircraft fuselage (Embraer E190) with Aluminum alloy and CFRP material, by the aid of a drop test in ANSYS (14.5)-Workbench solver and compare the results with design changes made on the fuselage.

Keywords - Carbon Fiber Reinforced Polymer (CFRP), Computer Aided Design (CAD), Fuselage, Drop-test, Explicit Dynamic, Finite Element Method/Analysis (FEM/A), Semi-Monocoque

\section{INTRODUCTION}

The safety of the human life has been a very sought after topic, when it comes to the matter of transportation. The transportation may be by road or by water or by air but the safety is the key issues that need to be concerned, as many devastating incidents have occurred in the past that could terrify human beings. So in order to prove the safety of the human life being priority the automotive industries had to prove their product to be safer and a convenient one. This lead to development of many methods like the Crash-test of the car, drop test of aircrafts and wind tunnel tests to ensure the aerofoil shapes effectiveness etc.

\author{
SREERAJENDRA \\ Associate Professor \\ Industrial Automation and Robotics, \\ Department of Mechanical Engineering, \\ Malnad College of Engineering, Hassan, Karnataka, \\ India
}

The crashworthiness of any automotive model has been a very important and sought-after issue to ensure the safety of the human life. But the conventional methods for ensuring the safety in an aircraft was by the Drop-Test of the civilian aircraft, which included the real aircraft to be used for the purpose, along with the manikins to serve the study with possible damages that could happen to the passengers. This needed a huge amount of money invested on a destructive method of analysis.

The development of computer softwares came to be proven very useful in the regard of designing at first, but slightly later even the analysis and simulation of the certain conditions mentioned above and beyond them were able to be proved effective and efficient to provide the results for any time step and boundary conditions that suit the condition of the system to resemble the actual process in real world.

The civilian aircrafts have a wide range of manufacturers like Boeing, Airbus, Lockheed Martin etc. Similar to these wellknown manufacturers a Brazilian based Aero-manufacturer Embraer made its debut in 1999. The Embraer E-Jet family is a series of narrow-body short to medium range twin-engine jet air-liners manufactured by Brazilian aerospace manufacturer.

Recently an aircraft Embraer E-190 manufactured by this Aero-manufacturer, had a crash in the recent issue of July2018. The investigation shows that both major and minor injuries have occurred whereas no loss of life has been reported. However, the Aircraft fuselage was said to be found broken near the wing intersection of the aircraft and the commuters were able to escape out of the aircraft through that particular broken fuselage area. Also extensive research has been done to find the reason for the breaking of the fuselage at that particular section, and also results confirmed that the material utilized for the construction of the fuselage was 
Aluminum alloy. So this work is focused regarding the comparison of the utilization of the CFRP (Carbon Fiber Reinforced Polymer) material over the utilization of the conventional Aluminum alloys for the fuselage construction. Specifically the ANSYS- Workbench module has been utilized for carrying out this FEM software simulation of Explicit Dynamic Analysis of the specified area of Embraer E190 aircraft as shown in Fig.1. The fuselage section of the aircraft has been modeled and utilized for the drop test comparison of the two materials along with the result for the design modification.

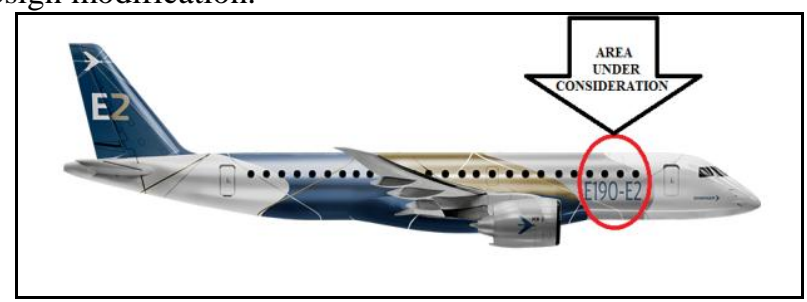

Fig.1. Embraer E190 depicting the area under consideration for drop-test analysis

The major concentration of this work is related to the Explicit Dynamic Analysis within the frame work of Finite Element Analysis. The effort is made for the comparison of the material properties of two materials that are extensively used in the aircraft manufacturing. The incident of the belly landing of an Embraer E190 aircraft led to the crashing of the aircraft fuselage during the year 2018 inspires the condition of droptest analysis and is towards the automation of the process of actual drop-test which is considered as destructive analysis in conventional practice. The automation of the crashworthiness of an aircraft can save both time and money for a larger extent. Since the actual aircraft model need not be necessarily used for the destructive method of analysis and the results can be obtain by the help of only the CAD model of aircraft being subjected to the analysis. However the CAD model being considered for the Explicit Dynamic Analysis of the fuselage drop-test is of the scale 1:10.

The Fuselage of the Embraer E-190 is a Semi-Monocoque type of fuselage and mainly consists of the following parts:

- Stringers: These are the longitudinal members that provide the structural support for the aircraft fuselage.

- Longerons: These are also the longitudinal members similar to the Stringers, whereas they are more slender and less in number than the stringers.

- Frame: These are similar to the ribs that are present in the human skeletal system, they are attached to the Stringers and longerons depending on their application and support the aircraft skin.

- Skin: The outermost surface that covers the entire aircraft fuselage and wings.

- Bulkhead: These are the supporting structures that are present in the Semi-Monocoque structures to join one fuselage structure to the next fuselage structure and thus forming the entire aircraft. They act as partitions between the fuselage structures.

The Semi-Monocoque structure along with its labeled parts is as shown in Fig.2

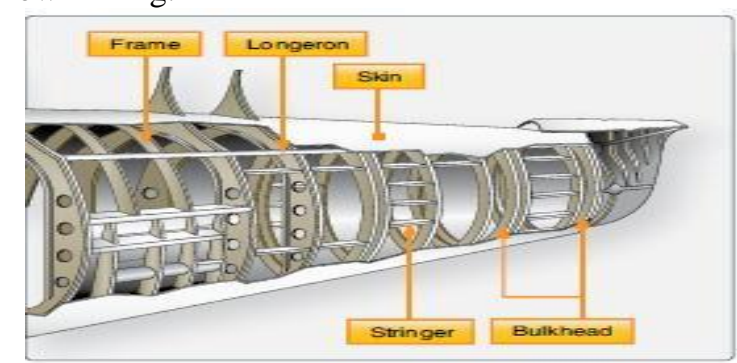

Fig.2. Semi-Monocoque fuselage structure with labled parts

The following Fig.3 shows the CAD model of the fuselage along with the labeled parts of the fuselage.

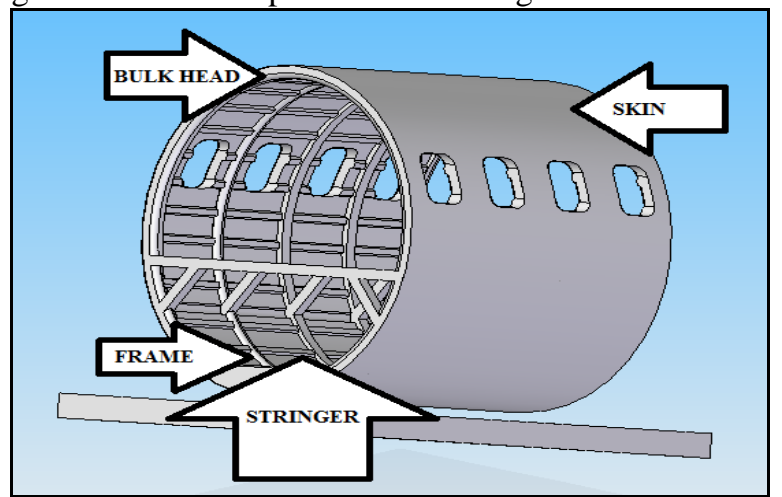

Fig.3. Labeled CAD model of fuselage

\section{METHODOLOGY}

The work is part of the FEM analysis, in which the Explicit Dynamic analysis is carried out on the aircraft fuselage structure for the condition of drop-test of fuselage using ANSYS-14.5.

FEM basically has the following steps to be followed in the preceding order as shown in the Fig.4.

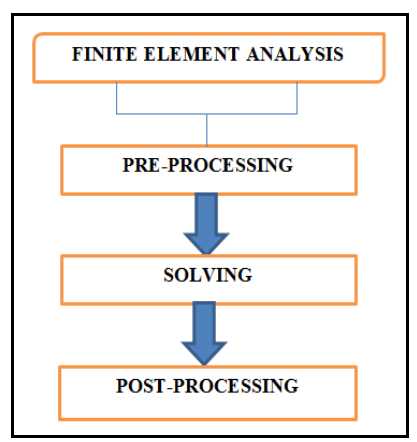

Fig.4. Steps in FEM 
Pre-processing- This step has the following sub-steps

- Geometrical construction

- Material selection

- Group formation

- Meshing and Mesh quality controlling

- Boundary conditions

- Time-step selection

Solving- This step is usually carried out by the software where the set of differential equations are solved in the form of Matrices to find the unknowns. This process has two types:

- Implicit analysis- The unknowns are found by the method of matrix inversion. It involves a large number of iterative steps where the obtained values of the previous steps are used for finding the values for next iteration. This involves a large amount of time investment and investment of specified proprietary solvers that can solve the matrices for unknowns. This method is applicable if the process is rather slower and the strain rates effects are minimal.

- Explicit analysis- This method is used when the solution needed also incorporates the velocity and acceleration to the solving conditions. Usually the mass matrices are considered to be diagonal matrices and the inversion process of the diagonal matrices is comparatively easier than the actual matrices. The time step needs to be essentially smaller than the travelling of the sound wave. Also the Explicit analysis can provide faster results for dynamic equilibrium conditions. Explicit method of analysis can be used when the velocity of the system under consideration becomes nearly equal to $10 \mathrm{~m} / \mathrm{s}$.

Post-processing- This step is the final and concluding step where the determined unknown values from the matrices are represented in the form of the color full images for the desired outputs and the values are depicted on the geometrical CAD model provided by user in the pre-processing step.

The steps considered during this particular analysis are as follows:

Pre-processing:

- Geometrical CAD model:

This is carried out using the Solid-Edge software environment, the following Fig.5 and Fig.6 shows the basic geometrical CAD model of the Fuselage section in Solid-Edge and ANSYS-geometry module respectively.

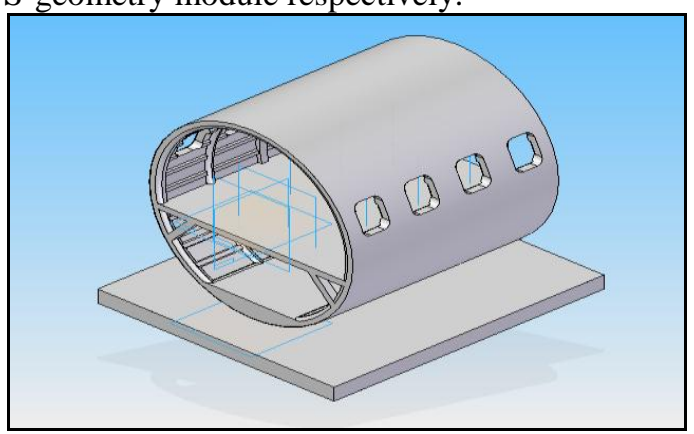

Fig.5. Geometrical CAD model in Solid-Edge environment

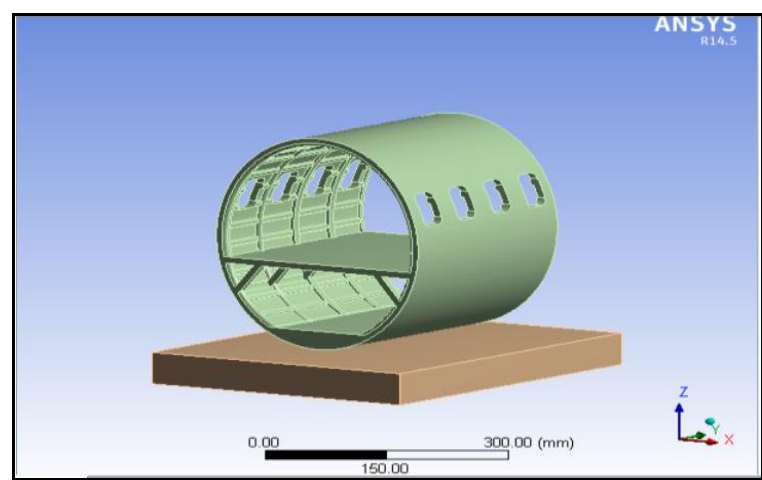

Fig.6. Imported CAD model in ANSYS-Geometry module The modified CAD geometry is as shown in Fig.7. The reinforcements are provided with the idea of reducing the Total Deformation that occurred in the basic model. The reinforcement is of $3 \mathrm{~mm}$ thickness in the modified model as the actual scale used for analysis is 1:10 in scale.

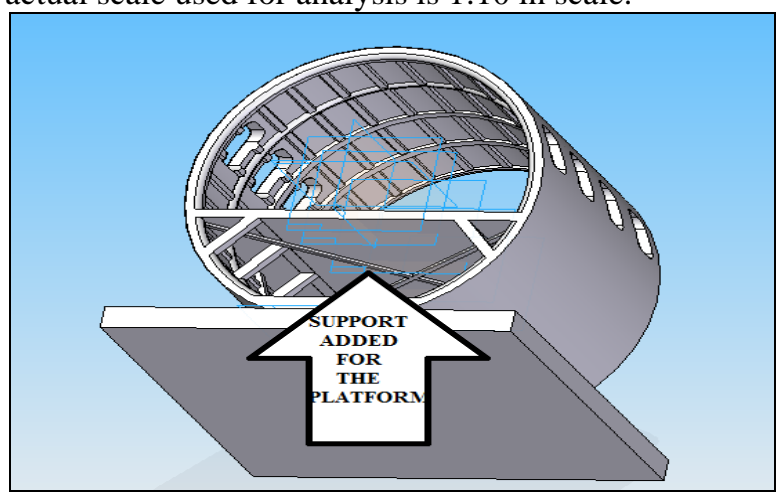

Fig.7. Modification made in CAD model

- Material Selection:

The material properties for the materials considered in the simulation are tabulated in Table.1 (D. Anitha et al. 2017).

Table.1. Material Properties table

\begin{tabular}{|c|c|c|c|}
\hline & FUSELAGE & FUSELAGE & GROUND \\
\hline Properties & $\begin{array}{c}\text { Aluminum } \\
\text { alloy }\end{array}$ & $\begin{array}{c}\text { CFRP } \\
\text { material }\end{array}$ & $\begin{array}{c}\text { Concrete } \\
\text { NL }\end{array}$ \\
\hline $\begin{array}{c}\text { Density } \\
\left.\text { (kg/m }{ }^{3}\right)\end{array}$ & 2810 & 1600 & 2300 \\
\hline $\begin{array}{c}\text { Young's } \\
\text { modulus } \\
(\text { Pa) }\end{array}$ & $2 \mathrm{E}+10$ & $7 \mathrm{E}+10$ & $3 \mathrm{E}+10$ \\
\hline $\begin{array}{c}\text { Poisson's } \\
\text { ratio }\end{array}$ & 0.3 & 0.1 & 0.18 \\
\hline $\begin{array}{c}\text { Bulk } \\
\text { modulus } \\
\text { (Pa) }\end{array}$ & $1.67 \mathrm{E}+11$ & $2.917 \mathrm{E}+10$ & $1.56 \mathrm{E}+10$ \\
\hline $\begin{array}{c}\text { Shear } \\
\text { modulus } \\
\text { (Pa) }\end{array}$ & $7.69 \mathrm{E}+10$ & $3.018 \mathrm{E}+10$ & $1.27 \mathrm{E}+10$ \\
\hline
\end{tabular}


- Mesh:

The meshed fuselage model is as shown in Fig.8.

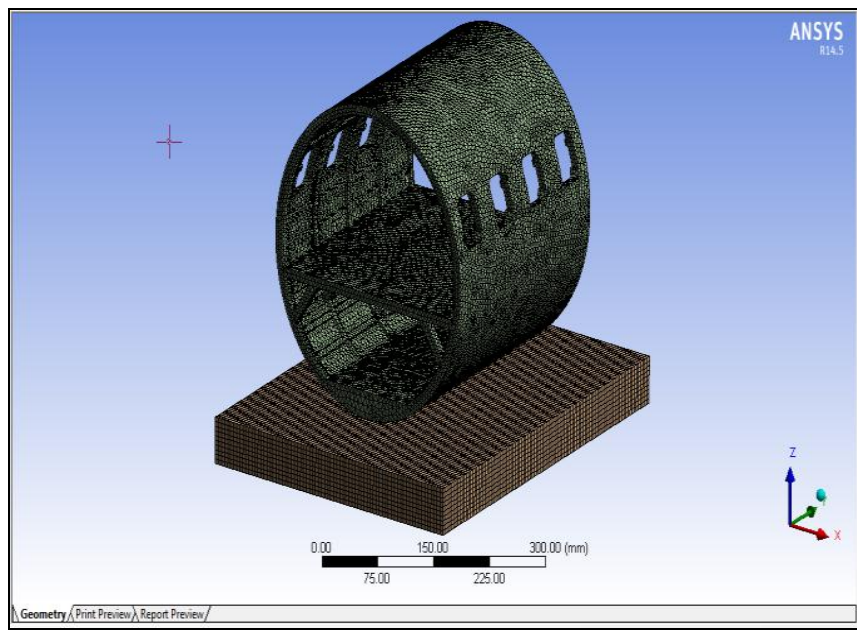

Fig.8. Meshed fuselage image

- Time step and Boundary condition:

Time is considered to be $0.003 \mathrm{sec}$ and the boundary condition are as shown in Fig. 9 with velocity being v=9.134m/s.

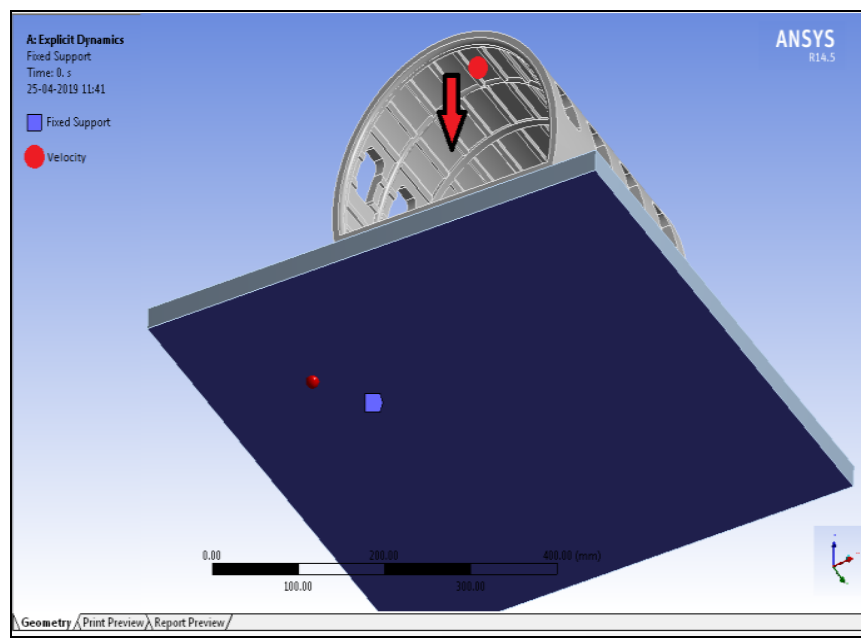

Fig.9. Boundary condition for drop-test

\section{RESULTS}

The results considered are the Equivalent Von-Mises Stress, Total Deformation and the Equivalent Von-Mises strain for the Aluminum and the CFRP material for the basic model and the CFRP material for the Modified model.
Basic model:

- Aluminum Alloy:

The Equivalent Von-Mises Stress=491.2MPa and is as shown in Fig. 10.

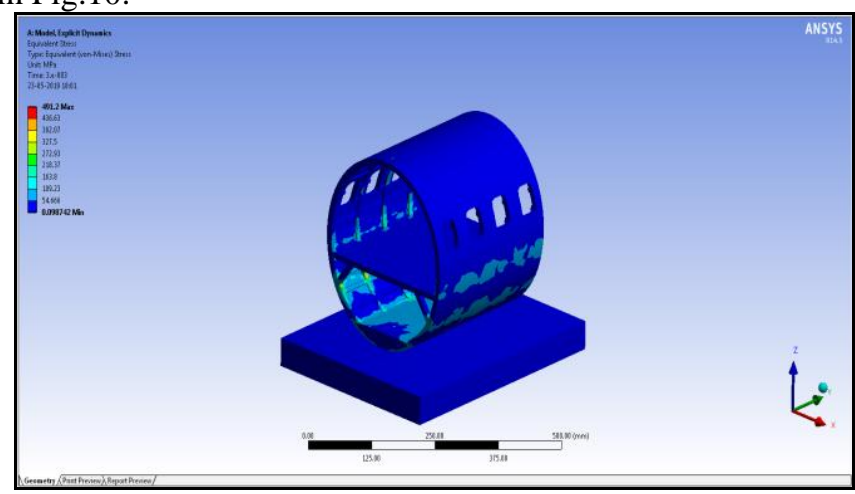

Fig.10. Equivalent Von-Mises stress for Al-alloy

The Total Deformation $=2.49 \mathrm{~mm}$ and is as shown in the Fig.11.

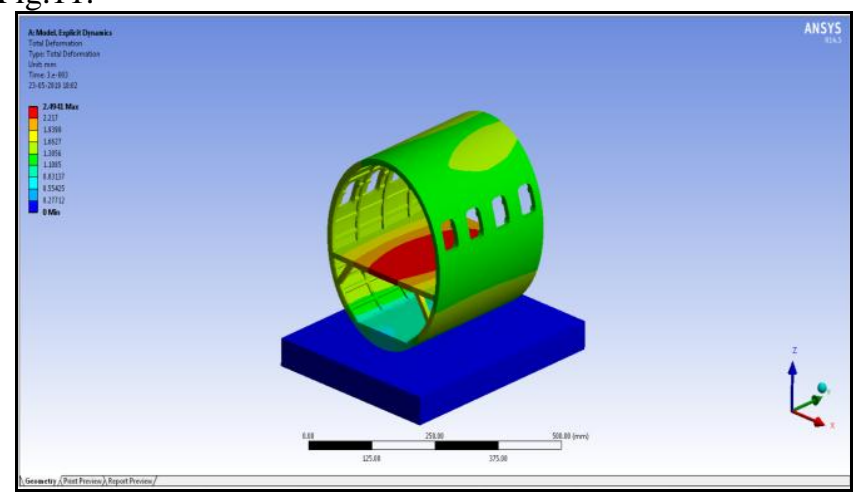

Fig.11. Total Deformation for Al alloy

The Equivalent Von-Mises Strain=0.0067 and is as shown in Fig.12.

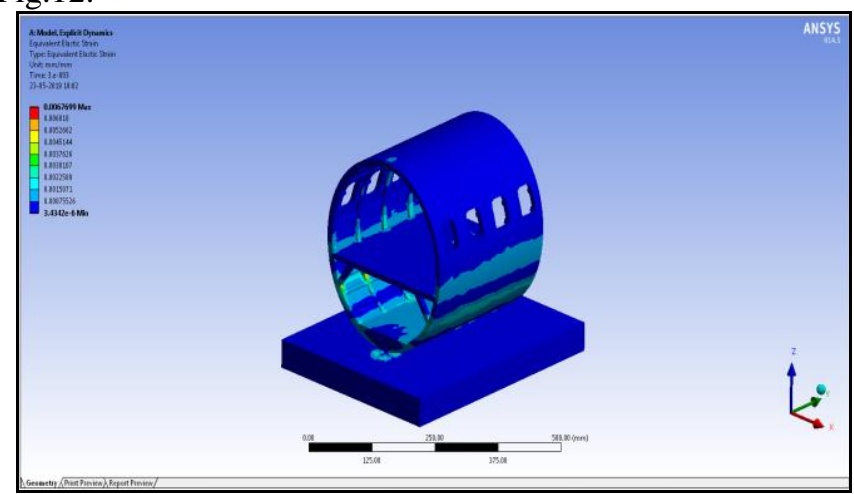

Fig.12. Equivalent Elastic Strain for Al alloy 
Basic model:

- $\quad$ CFRP material:

The Equivalent Von-Mises stress=366.97MPa is in Fig.13.

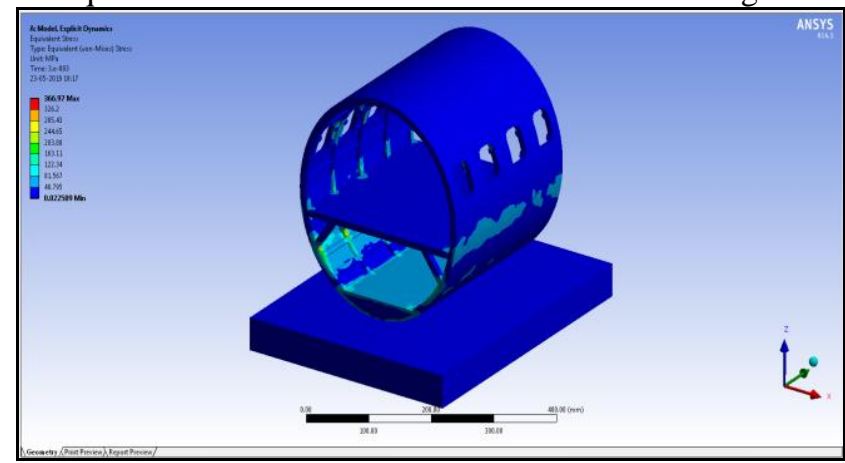

Fig.13. Equivalent Von-Mises stress for CFRP material

The Total Deformation $=0.926 \mathrm{~mm}$ is in Fig. 14 .

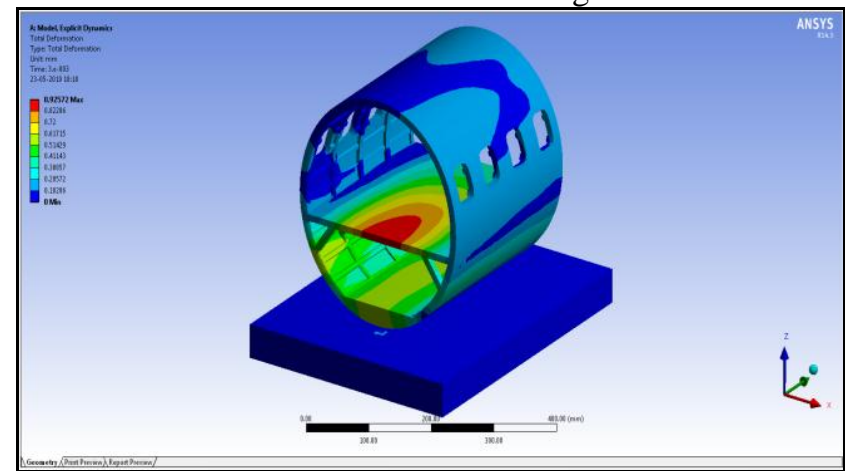

Fig.14. Total Deformation for the CFRP material

The Equivalent Elastic Strain $=0.00525 \mathrm{~mm} / \mathrm{mm}$ is in Fig. 15 .

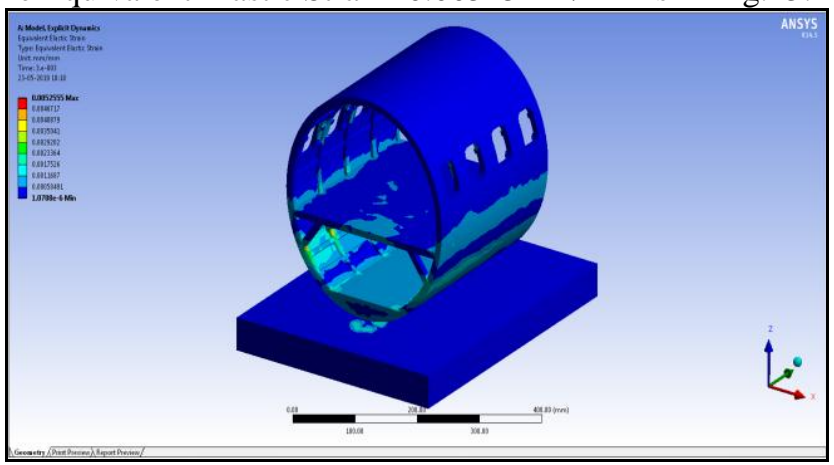

Fig.15. Equivalent Elastic Strain for CFRP material
Modified model:

- CFRP material:

The Equivalent Von-Mises stress=442.27MPa is in Fig.16.

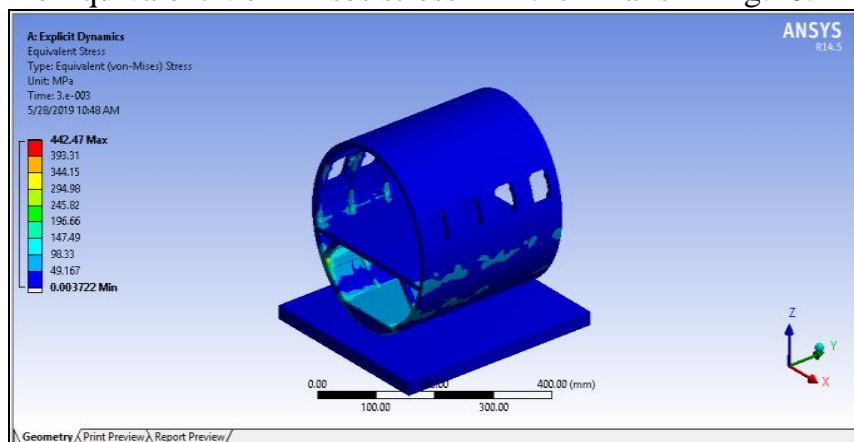

Fig.16. Equivalent Von-Mises stress for Modified CFRP model

The Total Deformation $=1.225 \mathrm{~mm}$ is in Fig. 17.

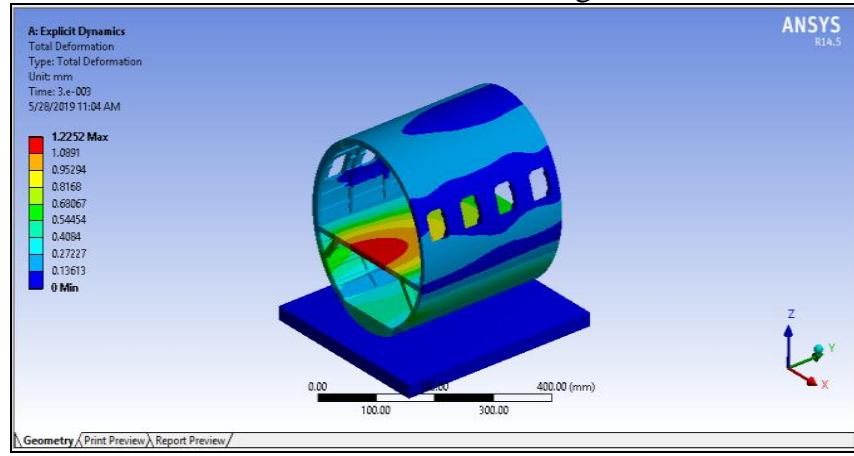

Fig.17. Total Deformation for the CFRP material

The Equivalent Elastic Strain $=0.0064 \mathrm{~mm} / \mathrm{mm}$ is in Fig. 18 .

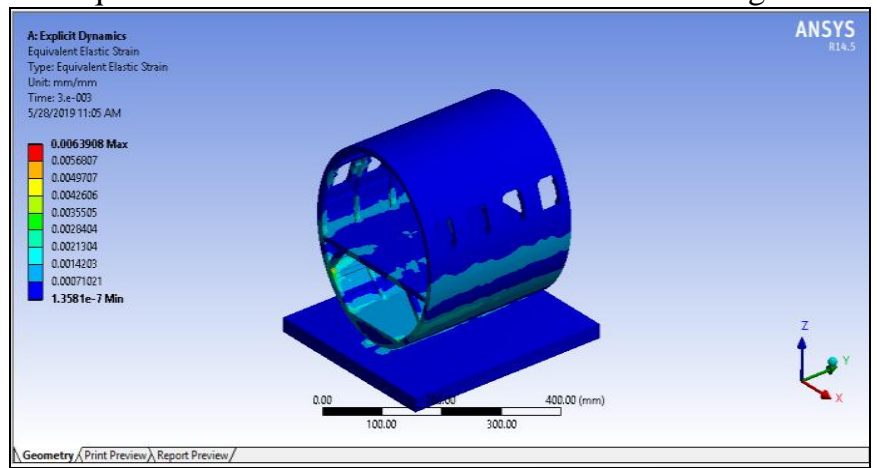

Fig.18. Equivalent Elastic Strain for CFRP material 


\section{International Journal of Engineering Applied Sciences and Technology, 2019 \\ Vol. 4, Issue 1, ISSN No. 2455-2143, Pages 61-66 \\ Published Online May 2019 in IJEAST (http://www.ijeast.com)}

\section{IV.CONCLUSION}

The comparison of the results for the Aluminum alloy and CFRP material are tabulated in Table.2.

Table.2. Result comparison for Aluminum alloy and the CFRP material for basic and the modified CAD models

\begin{tabular}{|c|c|c|c|}
\hline (Scale 1:10) & Basic model & Basic model & $\begin{array}{c}\text { Modified } \\
\text { model }\end{array}$ \\
\hline Parameter & Al alloy & $\begin{array}{c}\text { CFRP } \\
\text { material }\end{array}$ & $\begin{array}{c}\text { CFRP } \\
\text { material }\end{array}$ \\
\hline $\begin{array}{c}\text { Von-Mises } \\
\text { stress (MPa) }\end{array}$ & 491.2 & 366.97 & 442.47 \\
\hline $\begin{array}{c}\text { Total } \\
\text { Deformation } \\
\text { (mm) }\end{array}$ & 2.494 & 0.92572 & 1.225 \\
\hline $\begin{array}{c}\text { Equivalent } \\
\text { Elastic strain }\end{array}$ & 0.00676 & 0.00525 & 0.0064 \\
\hline
\end{tabular}

The values for the parameters being considered for the simulation are showing better results in case of the CFRP material than that of the Aluminum alloy for the basic design of CAD model. However for the design modifications made the results for the CFRP material are not satisfactory. This condition arrives due to addition of the extra mass to model caused by design modification made by adding of reinforcements to the platform. As the basic model of the CFRP material are far more comparatively better than the values obtained for the basic model of Aluminum alloy as well as CFRP material for modified model of fuselage. Hence CFRP material can be considered to be safe for the substitution of the Aluminum whereas the design modification made is not satisfactory.

\section{REFERENCE}

[1] Jose M. Vázquez-Moreno, Ruben Sánchez-Hidalgo, Estela Sanz-Horcajo, Jaime Viña, Raquel Verdejo, Miguel A. López-Manchado (2019), "Preparation and Mechanical Properties of Graphene/Carbon FiberReinforced Hierarchical Polymer Composites", 25-032019, doi:10.3390/jcs3010030.

[2] Aditya Sinha1*, Swathi Krishna2, Ajay B. Harish3, "Simulation Of Drop-Test For Aircraft's Fuselage", 0510-2018.

[3] K. Vamssi Venugopal, I. R. K. Raju (2018), "Design Optimization of Aircraft Fuselage Under Dynamic Responseby Using Finite Element Analysis”, ISSN (P): 2321-5747, Volume-6, Issue-1-2, 2018

[4] Karen E. Jackson, Karen E. Jackson, Justin D. Littell, Martin S. Annett, and Ian M. Haskin (2018), "Finite Element Simulations of Two verticaldrop Tests of F-28 Fuselage Sections", 02-2018, pp.1-71.

[5] Zhu Xianfei, Feng Yunwen, Xue Xiaofeng \& Qin Qiang (2017), "Evaluate the crashworthiness response of an aircraft fuselage section with luggage contained in the cargo hold", VOL. 22, NO. 4, 347-364, 12-10-2017.

[6] D Anitha, Ravi Kumar P, G K Shamili \& Bhavikatti Praveen (2017), "STRUCTURAL AND DROPTEST ANALYSIS OF HELICOPTER LANDING SKIDS", ISSN (P): 2249-6890; ISSN (E): 2249-8001 Vol. 7, Issue 5, 10-2017.

[7] D. Sukumar (2017), "MAINTENANCE OF AIRFRAME AND SYSTEMS DESIGN", 28-08-2017, pp.1-56.

[8] Derek Gransden, "Development of a Finite Element Model for Comparing Metal and Composite Fuselage Section Drop Testing”, 27-06-2017.

[9] Yiru Ren, Hanyu Zhang \& Jinwu Xiang (2017), “A novel aircraft energy absorption strut system with corrugated composite plate to improve Crashworthiness", DOI: 10.1080/13588265.2017.1301082, 27-03-2017.

[10] Ren Yiru, Xiang Jinwu, Zheng Jianqiang, Luo Zhangping (2016), "Crashworthiness analysis of aircraft fuselage with sine-wave beam structure", 24-02-2016,pp.403-410.

[11] Liu Xiaochuan, Guo Jun, Bai Chunyu, Sun Xiasheng, Mou Rangke (2015), "Drop test and crash simulation of a civil airplane fuselage section", 7-03-2015, pp.447-456.

[12] Ambri, Ramandeep Kaur (2014), "Spars and StringersFunction and Designing", ISSN (O): 2393-8609, Volume1, 9-2014. 